\title{
Elastic Maintenance Cycle Model of System Based on Multi-objective Particle Swarm Optimization Algorithm
}

\author{
Zhi-xia Zhang ${ }^{1, a}$, Hui Li ${ }^{2, b}$ \\ ${ }^{1}$ School of Xi'an University Of Architecture And Technology, Xi'an 710055, China; \\ ${ }^{2}$ School of Xi'an University Of Architecture And Technology, Xi'an 710055, China; \\ a1079353791@qq.com, ${ }^{\text {b329986188@qq.com }}$
}

Keywords: reliability; cost; maintenance cycle; multi-objective; particle swarm optimization

\begin{abstract}
The failure rate of it will increase with the increase of the system running time, the traditional periodic preventive maintenance can meet system failure characteristics, so improving the safety of gas pipeline and searching the system elastic maintenance period mode have the important practical significance. To improve the reliability of the system, control maintenance costs, according to the change of system failure rate, this paper will combine system reliability with the efficiency of system maintenance, on the theory of preventive maintenance, and use age reduction factor to establish reliability-maintenance cost multi-objective optimization model of the system. Combining with the engineering example, apply the multi-objective particle swarm optimization algorithm to solve the model example, in MATLAB platform.
\end{abstract}

\section{Introduction}

In order to avoid and reduce the huge loss caused by system failure, the regular maintenance of the system is essential, the traditional maintenance method includes preventive maintenance and breakdown maintenance. As the failure rate increases exponentially with the system working time, the periodic preventive maintenance does not achieve the desired effect, the elastic period preventive maintenance policy of the different maintenance intervals is more in line with the system failure modes [1]. Therefore, the multi-objective optimization model is established with the objective of reliability and maintenance cost. The maintenance cycle of the system is obtained by using the particle swarm algorithm [2]. The system can achieve the purpose of high reliability and low maintenance cost. Provide a theoretical of system repair work for the Enterprises.

\section{Basic assumptions of the model}

Because of the factors that affecting the preventive maintenance of natural gas pipeline system is too many, in order to study the model easily, the following assumptions are made as follows:

Assumption 1: The system just have two states, the system will be randomly in a normal operating state or maintenance state [3].

Assumption 2: The preventive maintenance of system is incomplete, it does not make the system restore the original state completely.

Assumption 3: The preventive maintenance is the minimum breakdown maintenance.

Assumption 4: For the system running time, the minimum maintenance time is neglected.

Assumption 5: The time value of money is negligible.

\section{System preventive maintenance cycle model}

In the limited runtime, Sequence preventive maintenance of the system can reduce the number of occurrences of random failures, reducing its operating costs. However, it will take some time and cost. Frequent preventive maintenance will cause over maintenance and increase the total repair costs, but inadequate maintenance will result in an increase of the failure rate and maintenance cost[4]. Therefore, in a limited time interval, it is important that controlling the frequency and duration interval of the preventive maintenance, establishing reasonable maintenance programs, 
reducing the total maintenance costs and increasing the reliability of the system.

According to the definition of reliability, life distribution density function and the life distribution function, the following relationship is established:

$$
F(t)=1-R(t)=1-\exp \left(-\int_{0}^{t} \lambda(t) d t\right)
$$

Among them, $\lambda(t)$ is the failure rate per unit time.

At present, the weibull distribution has been widely used in the life estimation, software reliability analysis and other fields. The failure rate function of weibull distribution $f(t)$ is as follows:

$$
f(t)=\frac{m}{\eta}\left(\frac{t-\gamma}{\eta}\right)^{m-1} \exp \left[-\left(\frac{t-\gamma}{\eta}\right)^{m}\right] \quad(\gamma \leq t ; m, \eta>0)
$$

Among them, $\eta$ is scale parameter; $m$ is shape parameter; $\gamma$ is location parameter. Then, cumulative failure probability density function $F(t)$ is as follows:

$$
F(t)=1-\exp \left[-\left(\frac{t-\gamma}{\eta}\right)^{m}\right] \quad(\gamma \leq t ; m, \eta>0)
$$

Failure rate function is as follows:

$$
\lambda(t)=\frac{m}{\eta}\left(\frac{t-\gamma}{\eta}\right)^{m-1} \quad(\gamma \leq t ; m, \eta>0)
$$

The research work of this paper is to determine the maintenance times $N \in\{1,2, \mathrm{~K}\}$ in $[0, T]$ ( $T$ is constant), the interval of preventive maintenance is $\varepsilon_{i}(i=1,2, \mathrm{~K}, N)$, the minimum time interval is $\varepsilon_{\text {min }}$, system for the time $i$ preventive maintenance time is $\theta_{i} \in(i=1,2, \mathrm{~K}, N)$.

The age reduction factor $\alpha$ is introduced to describe the dynamic changes of the system before and after repairing. Assumes that the system has run $\varepsilon_{i}$ before the repairing of time $i$, after maintenance, the age reduction of system changes to the status of $\varepsilon_{i}-\alpha_{i} \varepsilon_{i}$, the age reduction amount is $\alpha_{i} \varepsilon_{i}$. The failure rate of the system in the $i$ preventive maintenance intervals is $\lambda_{i}(t)$ :

$$
\lambda_{i}(t)=\lambda\left(t+\sum_{j=1}^{i-1}\left(1-\alpha_{k}\right) \varepsilon_{k}\right) \quad(i=1,2, L, N)
$$

Then, getting the $R_{i}(t)$ :

$$
R_{i}(t)=\exp \left(-\int_{0}^{t} \lambda\left(t+\sum_{j=1}^{i-1}\left(1-\alpha_{k}\right) \varepsilon_{k}\right) d t\right)
$$

In this paper, the system maintenance cost contains the total minimum maintenance cost of the system during the interval of preventive maintenance, the total maintenance cost of the system unscheduled preventive maintenance, and the total shutdown losses caused by maintenance.

To avoid the dynamic changes of the system preventive maintenance reliability, obtained an average reliability of the system. Therefore, the system reliability-maintenance cost multi-objective optimization model is as follows:

$$
\begin{aligned}
& \operatorname{Max} \quad R_{a}\left(N, \varepsilon_{i}\right)=\frac{\sum_{i=1}^{N+1} \int_{0}^{\varepsilon_{i}} \exp \left(-\int_{0}^{t} \lambda\left(t+\sum_{j=1}^{i-1}\left(1-\alpha_{k}\right) \varepsilon_{k}\right) d t\right) d t}{\sum_{i=1}^{N+1} \varepsilon_{i}} \\
& \text { Min } \quad C\left(N, \varepsilon_{i}\right)=\sum_{i=1}^{N+1} \int_{0}^{\varepsilon_{i}} c_{c m} \cdot \lambda\left(t+\sum_{j=1}^{i-1}\left(1-\alpha_{k}\right) \varepsilon_{k}\right) d t+\sum_{i=1}^{N} c_{p m}\left(\alpha_{i}, \varepsilon_{i}, \theta_{i}\right)+\sum_{i=1}^{N} c_{p t} \theta_{i}
\end{aligned}
$$

s.t. $\quad \sum_{i=1}^{N+1} \varepsilon_{i}+\sum_{i=1}^{N} \theta_{i} \leq T \quad 0 \leq \alpha_{i} \leq 1$ 


\section{Engineering example}

In this paper, the example is the specific data of an enterprise, in the MATLAB environment, using particle swarm optimization to solve it. The age reduction factor is $\alpha_{i}=0.90$. The specific numerical values of the engineering example are shown in Table 1.

Tab.1 Specific numerical of the examples

\begin{tabular}{cccccccc}
\hline $\begin{array}{c}\text { Finite } \\
\text { interval } \\
: T \\
(\text { day })\end{array}$ & $\begin{array}{c}\text { Preventive } \\
\text { maintenance } \\
\text { time: } \theta_{i}\end{array}$ & $\begin{array}{c}\text { The } \\
\text { minimum } \\
\text { time between } \\
\text { maintenance: } \\
\varepsilon_{\text {min }}\end{array}$ & $\begin{array}{c}\text { Stop loss } \\
\text { per unit } \\
\text { time }: c_{p t} \\
\text { (yuan) }\end{array}$ & $\begin{array}{c}\text { Every time the } \\
\text { minimum } \\
\text { maintenance } \\
\text { cost: } c_{c m} \\
\text { (yuan) }\end{array}$ & $\begin{array}{c}\text { The cost of } \\
\text { preventive } \\
\text { maintenance: } c_{p m} \\
\text { (yuan) }\end{array}$ & $\begin{array}{c}\text { Shape } \\
\text { parameter : parameter: } \\
m\end{array}$ & $\begin{array}{c}\text { Scale } \\
\eta\end{array}$ \\
\hline$[0,600]$ & 2 & 2 & 1000 & 300 & $c_{p m}=100+0.2 \alpha_{i} \varepsilon_{i}$ & 2 & 50 \\
\hline
\end{tabular}

Because the objective function of the model is to find the maximum value and the minimum value. Therefore, in the process of using MATLAB programming, changing the $R$ to the $1 / R$, this makes it easy to strike the optimal solution. By calculation, the optimal solution set is shown in Figure 1.

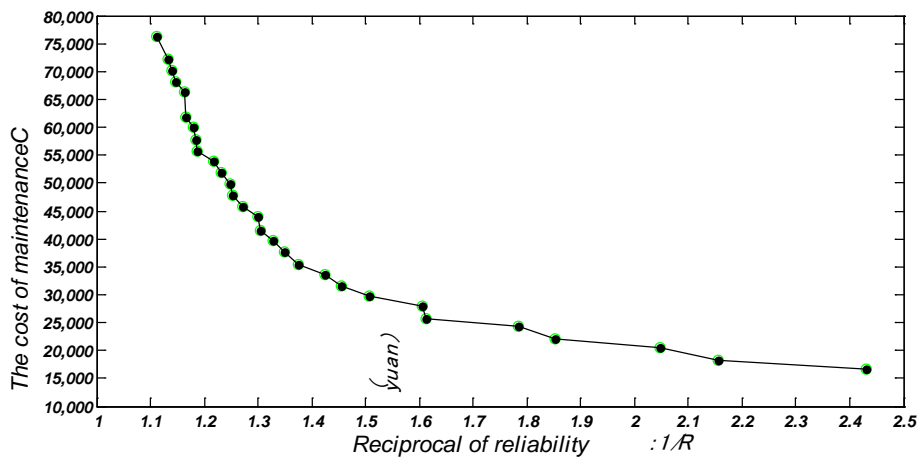

Fig. 1 Optimal solution set in MATLAB platform

Each point in the graph is an optimal solution, and each point corresponds to a maintenance plan, which includes the cost, reliability, and time interval of maintenance. Selecting several solutions and listing them in the Table 2.

Tab.2 Reliability and cost of every optimal solution

\begin{tabular}{cccc}
\hline Relibility: $R$ & Cost: $C$ & Relibility: $R$ & Cost: $C$ \\
\hline 0.88309 & 67832.2 & 0.618973 & 25657.2 \\
0.76219 & 41733.2 & 0.54936 & 21903.5 \\
0.719556 & 35670.3 & 0.466507 & 18340.2 \\
0.681 & 31723 & 0.392471 & 17306.2 \\
\hline
\end{tabular}

Selecting three sets of data from the Table 2 , then obtain the following results.
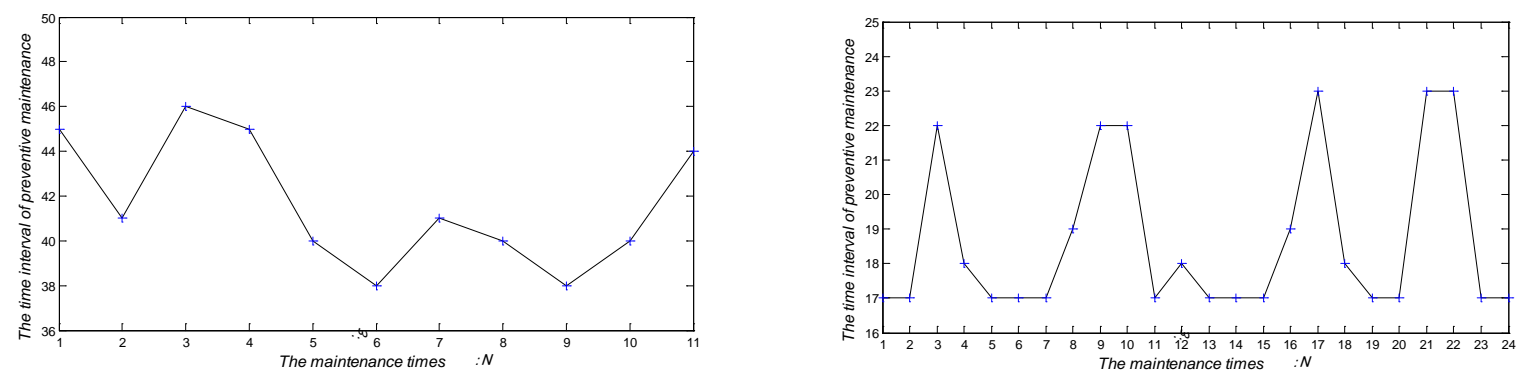

Fig. 2 System maintenance times and maintenance intervals when $\mathrm{R}$ is 0.6189 and 0.8831

From the results of Table 2, it can be seen that different systems have different maintenance costs, with the continuous improvement of reliability, maintenance costs is also rising. When the reliability increased from 0.6189 to 0.8831 , upgrade 42175 yuan. This shows that, in order to achieve higher reliability, enterprises need to pay higher maintenance costs, and each kind of 
different maintenance plan also has different maintenance cycle and maintenance times.

Figure 2 shows that when reliability is 0.6189 , the number of system maintenance is 11 times, and the time interval is about 40 days; when reliability is 0.8831 , the number of system maintenance is 24 times, and the tine interval is about 20 days. Analysis the results, the maintenance times increases with the increase of the reliability, the maintenance time interval decreases with the increase of reliability.

\section{Conclusion}

In order to improve the reliability of the system, the safety of the system is increased, the maintenance time of the system is reduced, while service intervals are presented characteristic changes, forming a flexible maintenance cycle, and verifying the feasibility of the model. Significantly different with the traditional fixed cycle maintenance, the model provide a basis for the preventive maintenance of the enterprise, the enterprise can choose a suitable maintenance plan according to their own situation, to prevent the huge loss of natural gas pipeline damage.

\section{Acknowledgments}

This study was supported by the Project of Natural Science Foundation of Shanxi Province (2014JM9375).

\section{References}

[1] Lapa, C.M.F., Pereira, C.M.N.A., and Barros, M.P. A model for preventive maintenance planning by genetic algorithms based in cost and reliability[J], Reliability Engineering and System Safety. 2006, 91(2).

[2] J. J. Liang, and P. N. Suganthan. Dynamic Multi-Swarm Particle Swarm Optimizer[C]. In Proceedings of IEEE International Swarm Intelligence Symposium(SIS 2005), PP. 124-129, 2005.

[3] Tsai, Y.T.; Wang, W.S.; Teng, H.Y. Optimizing preventive maintenance for mechanical components using genetic algorithms , Reliability Engineering and System Safety, 2001, 74: 89-97.

[4] Lie, C.H.; Chun, Y.H. An algorithm for preventive maintenance policy, IEEE Transactions on Reliability, 1986, 35(1):71-75. 